\title{
Social deprivation, ethnicity and violent incidents on acute psychiatric wards
}

\author{
J. D. Sheehan, T. Hardie and J. P. Watson
}

\begin{abstract}
A retrospective comparative study of violent incident forms covering the acute general adult wards at a London feaching hospltal and a district general hosplital was performed. Although no significant difference was observed between the overall rates of reported violent incidents, there was a significant increase in the proportion of violent incidents directed at persons in the inner city hosplital. Grade 3 incidents were rare. Caribbean patients were over-represented among the perpetrators.
\end{abstract}

There is a growing concern about violent incidents in hospitals (Walker \& Seifert, 1994). It is unclear how the rate of incidents varies between hospitals based in different catchment areas, which differ in terms of social deprivation. The ethnic composition of the catchment area population is of relevance as studies have produced conflicting results regarding patients of Afro-Caribbean origin (Noble \& Roger, 1989; Walker \& Seifert, 1994).

We hypothesised that there would be a greater number of violent incidents and that they would be of greater seriousness on acute psychiatric wards in a socially deprived area compared with a less socially deprived one. We also examined the effect of ethnicity on the rate of violent incidents in a socially deprived catchment area.

\section{The study}

We examined violent incident forms for a 12 month period for all the acute general adult psychiatric wards at Guy's Hospital, London and at Maidstone Hospital, Kent. Guy's Hospital is an inner city, university teaching hospital with four acute wards and 48 beds. It serves a catchment area of 94000 . Maidstone is a district general hospital with one acute ward and 35 beds. In a semi-rural setting, its catchment area population is 105000 .
The UPA Jarman Score for the Guy's catchment area (Lewisham and North Southwark District Health Authority) is $\mathbf{3 6 . 3 0}$ and for Maidstone is 18.85 , indicating that Guy's serves a socially deprived catchment area.

The violent incident forms record basic demographic details and allow for a written description of the violent incident. We based our measure of seriousness of incidents on that of Fottrell (1980) but excluded incidents of self-harm and included incidents which involved damage to property. Incidents involving persons were regarded as more serious than those just involving property. We described three levels of violence with grade 1 incidents involving no damage, grade 2 involving only minor damage or injury not requiring treatment, and grade 3 representing serious damage to property or injury requiring treatment. We rated incidents based on their potential seriousness as well as the actual outcome of the incident. Two of us (JS \& TH) rated each incident blindly and discussion of cases took place where disagreement occurred to achieve a consensus.

We collected demographic details and diagnoses from the case-notes and examination of hospital computer databases. Classification of ethnic group was based upon information from these sources. Details of the catchment area ethnicity profile were obtained from hospital management.

The study period at Guy's was from February 1993 to January 1994 and at Maidstone was from July 1993 to June 1994 . Comparison was made between the two study areas regarding the overall number of violent incidents, the seriousness of the incidents and the ethnicity of the perpetrators. To allow a more direct comparison of wards we calculated the rate of incidents per bed per year. We assumed $100 \%$ 
bed occupancy and that every patient had an equal chance, each day, of perpetrating a violent incident. Statistical analyses used the $x^{2}$ test to compare proportions.

\section{Findings}

The overall rate of violent incidents was low. There were 50 incidents at Guy's and 41 at Maidstone. The rate of incidents was similar in both centres and slightly lower at Guy's (1.04/ bed/year at Guy's and $1.17 / \mathrm{bed} /$ year at Maidstone). The majority of incidents were grade 1 (Guy's/Maidstone: 43/29) with fewer grade $2(6 / 11)$ and one grade 3 at both locations. The grade 3 incident at Guy's was an attempted stabbing of a staff member and at Maidstone an attempted fire-setting of the psychiatric ward. There were more admissions to Guy's (849) than to Maidstone (292) during the study period.

Differences emerged regarding the victims involved (Table 1). At Guy's, there was a greater proportion of violent incidents directed at persons (i.e. nurses, other patients, doctors and other individuals) than at property. Compared to Maidstone, this was highly significant $(P=0.01)$.

As regards perpetrators, there were 35 at Guy's and 27 at Maidstone. Young males predominated in both centres, (male/female: Maidstone 18/9; Guy's 21/4). Nine patients (three male, six female) at Guy's and seven (six males, one female) at Maidstone were multiple perpetrators.

The majority of perpetrators were informal, $54 \%$ at Guy's and $61 \%$ at Maidstone. However, ethnic differences were found. Nine out of 16 Caribbean but only three out of 14 white European perpetrators were detained under the provisions of the Mental Health Act 1983.

At Guy's, $46 \%$ of the perpetrators were defined as Caribbean. As $11 \%$ of admissions at Guy's are patients of Caribbean origin, the figures suggest that Caribbean patients are

Table 1. 'Victims' of incidents at Guy's Hospital and Maidstone Hospital

\begin{tabular}{lll}
\hline 'Victim' & Maidstone & Guy's \\
\hline Property & 20 & 13 \\
Nurse & 12 & 29 \\
Patient & 9 & 12 \\
Doctor & 1 & 1 \\
Other & 1 & 3 \\
\hline
\end{tabular}

over-represented in the population who commit violent incidents. The difference in proportions was significant at the $5 \%$ level $(P<0.05)$. White Europeans accounted for $66 \%$ of admissions but only $40 \%$ of violent incidents. Black Africans constituted 9\% of admissions and $6 \%$ of incidents. 'Others' represented $12 \%$ of admissions and $9 \%$ of incidents.

\section{Comment}

Investigation of violent incidents on acute psychiatric wards is made difficult by numerous confounding factors. It has been suggested that counting violent incidents by use of incident forms may underestimate the number of incidents (Haller \& Deluty, 1988) although this may not be so (Aiken, 1982).

The study did not support the hypothesis that there would be a greater number of violent incidents in the urban setting. However, the finding that Guy's had a greater proportion of violent incidents directed at persons would appear to support the hypothesis that there is a difference between the two settings and supports the clinical impression that staff working in an inner city hospital are exposed to more personal violence. It is possible also that, in an inner city setting where the wards are busier, there is a tendency to record personal violent incidents and to be less concerned about reporting incidents involving property. From the admission figures, it is clear that the wards at Guy's are far busier than at Maidstone. However, it is possible that the difference reflects other actors such as the different topography of the two settings or crowding (Palmstierna et al, 1991).

Although the absence of Caribbean patients at Maidstone is a clear reflection of the catchment area, the over-representation at Guy's, compared with the proportion admitted, was unexpected. Nonetheless, this is in line with work showing that this group are more often admitted on compulsory orders than white Europeans (Harrison et al, 1984). A possible explanation is that these patients are admitted later in the course of their illness, have greater morbidity and consequently are more likely to be involved in violent incidents.

In conclusion, the study indicates that there is a significantly increased rate of violent incidents directed towards persons at Guy's hospital than at Maidstone, suggesting that levels of violence are increased in inner city. 
socially deprived catchment areas. Caribbeans are over-represented in the violent group at Guy's but, because they are more likely to be detained under the Mental Health Act, definite conclusions regarding their overrepresentation cannot be drawn.

\section{Acknowledgements}

The authors wish to thank Dr. Sivakumar for his assistance. The study was supported in part by a Priory Research Fellowship.

\section{References}

AIKEN, G. J. M. (1982) Violence on the semi-secure ward of a psychiatric hospital. Medicine Science and the Law. 22. 203-209.

FOTTRELL, E. (1980) A study of violent behaviour amongst patients in a psychiatric hospital. British Journal of Psychiatry, 136. 216-221.
HALLER, R. M. \& DEUTY, R. H. (1988) Assaults on staff by psychiatric in-patients. A critical review. British Journal of Psychiatry. 152. 174-179.

HARRISON. G. INEICHEN. B. SMITH. J. et al (1984) Psychiatric hospital admissions in Bristol II. Social and clinical aspects of compulsory admission. British Journal of Psychiatry, 145, 605-611.

NOBLE, P. \& ROGER, S. (1989) Violence by psychiatric inpatients. British Journal of Psychiatry. 165, 384-390.

Palmstierna, T., Huitreld, B. \& Wistedt, B. (1991) The relationship of crowding and aggressive behaviour on a psychiatric intensive care unit. Hospital and Community Psychiatry. 42, 1237-1240.

WALKER, Z. \& SEIFERT, R. (1994) Violent incidents in a psychiatric intensive care unit. British Journal of Psychiatry, 164. 826-828.

*John D. Sheehan, Research Fellow; T. Hardie, Registrar, and J. P. Watson, Professor of Psychiatry, Division of Psychiatry and Psychology, UMDS, Guy's Hospital, London.

*Correspondence Mater Misericordiae Hospital. Eccles Street, Dublin 7, Ireland.

\section{Prevention of Anxiety and Depression in Vulnerable Groups}

\section{Joanna Murray}

The scope of this review, commissioned by the Department of Health, is the common mental disorders of anxiety and depression occurring in adults in the community. It considers the possibilities for prevention in primary care. This combination of basic conceptual and research information provides a practical framework of preventive strategies for the primary care team. Social factors in aetiology are examined in detail, and epidemiological data is used to consider vulnerability factors and to identify high risk groups. There is also a thorough review of risk for common mental disorders.

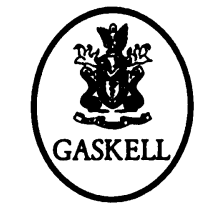

$\bullet £ 7.50 \bullet 112 p p . \bullet 1995 \bullet$ ISBN 0902241877

Available from bookshops and from the Publications Department, Royal College of Psychiatrists, 17 Belgrave Square,

London SW1X 8PG (Tel. 0171-235 2351 extension 146) 